\title{
Ineffectiveness of myrrh-derivative Mirazid against schistosomiasis and fascioliasis in humans
}

\author{
M.M. Osman, ${ }^{7}$ H.A. El-Taweel, ${ }^{7}$ A.Y. Shehab and H.F. Farag ${ }^{7}$
}

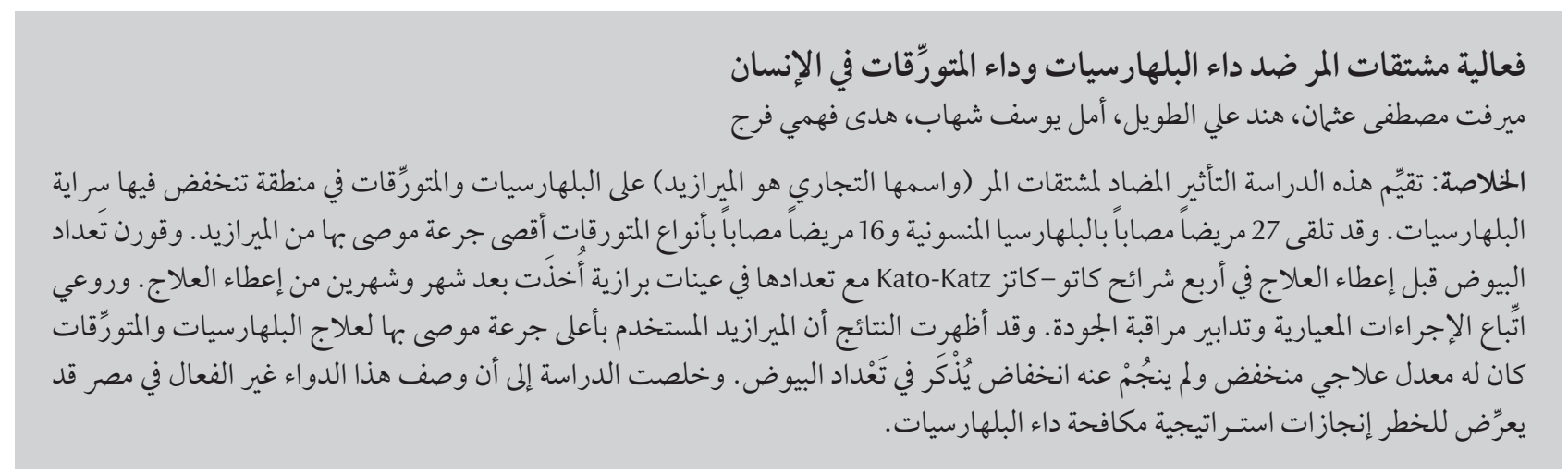

ABSTRACT The present study assessed the schistosomicidal and fasciolicidal actions of the myrrh-derivative Mirazid ${ }^{\circledR}$ in an area of low schistosomiasis transmission. A total of 27 patients infected with Schistosoma mansoni and 16 with Fasciola spp. received the maximum recommended dose of Mirazid. Pretreatment egg counts in 4 Kato-Katz slides were compared with similar counts in stool samples collected 1 and 2 months after treatment. Standard procedures and quality control measures were followed. The results revealed that Mirazid used as schistosomicidal or fasciolicidal agent in the maximum recommended dose has a low cure rate and produced a negligible reduction in egg counts. Prescribing such an ineffective drug in Egypt might endanger the achievements of the schistosomiasis control strategy.

Inefficacité du Mirazid (à base de myrrhe) dans le traitement de la schistosomiase et de la fasciolase chez l'homme

RÉSUMÉ La présente étude visait à évaluer l'action schistosomicide et fasciolicide du Mirazid ${ }^{\circledR}$, à base de myrrhe, dans une zone de faible transmission de la schistosomiase. Au total, 27 patients infectés par Schistosoma mansoni et 16 patients infectés par Fasciola spp. ont reçu la dose maximale recommandée de Mirazid. Le nombre d'œufs comptés avant traitement sur quatre lames Kato-Katz a été comparé au nombre d'œufs identifié dans les échantillons de selles recueillis un mois et deux mois après le traitement. Les résultats ont révélé que le Mirazid, employé en tant qu'agent schistosomicide ou fasciolicide à la dose maximale recommandée, est associé à un faible taux de guérison et induit une diminution négligeable du nombre d'œufs. La prescription d'un médicament aussi inefficace en Égypte peut compromettre les avancées de la stratégie de lutte contre la schistosomiase. 


\section{Introduction}

An anti-schistosomal action of myrrh, derived from a natural botanical source, was first described by Massoud and colleagues in 1996 [1]. They reported that a combination of resin, obtained from the plant by alcohol extraction and volatile oil, separated by water and steam distillation, produced complete elimination of worms in hamsters infected with Schistosoma mansoni. Subsequently, a combination of resin and volatile oil was used to treat 62 schistosomiasis patients in a dose of $11.5 \mathrm{mg} / \mathrm{kg} /$ day for 3 days. The number of eggs in stool samples decreased from 250 eggs per gram (epg) before treatment to 3 epg 8 weeks post treatment [2]. In another study, 204 schistosomiasis patients treated with myrrh in a dose of $10 \mathrm{mg} /$ $\mathrm{kg} /$ day for 3 days showed an initial cure rate of $91.7 \%$. Re-treatment of uncured cases with a second dose of $10 \mathrm{mg} / \mathrm{kg} /$ day for 6 days gave a cure rate of $76.5 \%$, increasing the overall cure rate to $98.1 \%$ [3].

Massoud et al. also studied the efficacy of myrrh in the treatment of 7 cases of human fascioliasis; eggs were not detected in the stool 3 weeks posttreatment and remained so throughout a follow-up period of 3 months [4]. Further clinical trials and experimental animal studies conducted in Egypt approved these anti-helminthic actions of myrrh [5-9]. The Egyptian Ministry of Health has licensed it as a treatment for human schistosomiasis and fascioliasis. In 2001, a pharmaceutical-grade myrrh product known as Mirazid ${ }^{\circledR}$ has been launched for clinical use. Further human studies have emphasized the efficacy of the commercial form of myrrh [10-15]. Successful advertising campaigns encouraged its use by physicians and private clinicians. Being of natural origin without overt side-effects, it gained great acceptance by the villagers who often preferred it over other effective anti-parasitic drugs.
In contrast to the previous findings, one experimental study failed to demonstrate a satisfactory anti-schistosomal action of different derivatives of myrrh, including the commercial preparation, tested at different doses against many strains of S. mansoni [16]. Furthermore, 2 randomized controlled clinical trials published in 2005 demonstrated negligible cure rates of Mirazid in schistosomiasis mansoni $[17,18]$.

In view of the great reliance on chemotherapy as the mainstay of schistosomiasis control strategy in Egypt, the present study assessed cure rates of $\mathrm{Mi}$ razid in human cases of schistosomiasis and fascioliasis.

\section{Methods}

\section{Study subjects}

The study included 31 schistosomiasis and 18 fascioliasis cases identified in a survey conducted in 2008 in Abis, an Egyptian rural area with a low schistosomiasis transmission rate [19]. The age of patients ranged from 15 to 30 years; $53 \%$ of them were males.

\section{Pretreatment stool examination}

Initial diagnosis of infection was based on egg detection by examination of 2 Kato-Katz slides (of $41.7 \mathrm{mg}$ each) prepared from a single stool sample [20]. On the 2 days preceding the day of treatment, patients were asked to provide stool samples. Eggs in 4 slides (2 slides from each sample) were counted and egg counts in stools were recorded. Patients who were negative for parasites on these days were excluded.

\section{Treatment}

Patients and parents of infected children were informed about the nature of Mirazid and the study protocol. After getting their consent to participate, Mirazid capsules were given in a dose of $600 \mathrm{mg}$ for 6 consecutive days, regardless of the patient's age or weight, as recommended by the manufacturer. The drug was given on an empty stomach and patients continued fasting for 1 hour posttreatment. Side-effects were recorded if reported by the patient.

\section{Cure evaluation}

Follow-up was performed 1 and 2 months post-Mirazid treatment. For each subject, 2 stool samples were collected on 2 consecutive days and 2 Kato-Katz slides were examined per sample. Schistosoma spp. and Fasciola spp. eggs were counted when detected. Viability of Schistosoma spp. eggs was assessed in the second follow-up period. Fresh stool samples were suspended in saline, sieved and left to sediment. Dechlorinated water was added to the sediment and left for $1 \mathrm{~h}$ at room temperature. The supernatant was exposed to light and examined with a hand lens for hatched miracidia. The sediment was examined microscopically for hatching miracidia, viable miracidia within unhatched eggs and for empty shells [21].

\section{Quality control}

All steps of slide preparation followed standard procedures under the authors' supervision. Slides were examined by well-trained technicians and the recorded egg counts were checked and revised by the authors. Patients received Mirazid capsules under the supervision of one of the investigators.

\section{Statistical analysis}

S. mansoni and Fasciola spp. egg counts were expressed in epg using the arithmetic mean of egg counts obtained from 4 slides, multiplied by 24 [20]. The geometric mean egg count (GMEC) was calculated in each follow-up period and compared with the pretreatment GMEC to calculate the percentage change in egg counts using the formula (1 - [GMEC/g after treatment/ GMEC/g before treatment]) × 100 . Statistical comparison of mean egg 
counts prior to and post-treatment were evaluated by paired sample $t$-test on egg counts.

\section{Results}

The day before Mirazid treatment, 4 schistosomiasis and 2 fascioliasis patients were found to be parasitologically negative and were not included in the study. Treated patients tolerated the drug well with no recorded side-effects. Among the schistosomiasis patients, only 4 out of 27 cases (14.8\%) were cured 1 month post-treatment and 3 of them re-excreted Schistosoma spp. eggs 1 month later, decreasing the cure rate to just 1 case $(3.7 \%)$.

All fascioliasis patients continued passing eggs in the 2 follow-up periods (Table 1). Among uncured schistosomiasis patients, GMEC rose from 63.5 [standard deviation (SD) 163.5] pre-treatment to 74.2 (SD 216.2) 1 month post-treatment, a $16.8 \%$ rise. One month later, a $3.5 \%$ reduction in GMEC was detected as compared with the pretreatment count. Statistically, these changes in GMEC were nonsignificant. Testing for viability in the second follow-up period revealed that all uncured subjects were passing viable ova.

In fascioliasis cases, the GMEC showed $29.4 \%$ reduction in the first

\begin{tabular}{|c|c|c|c|c|}
\hline \multicolumn{5}{|c|}{$\begin{array}{l}\text { Table } 1 \text { Schistosomiasis and fascioliasis cure rates } 1 \text { and } 2 \text { months after treatment } \\
\text { with Mirazid }\end{array}$} \\
\hline \multirow[t]{2}{*}{ Type of infection } & \multicolumn{2}{|c|}{ After 1 month } & \multicolumn{2}{|c|}{ After 2 months } \\
\hline & No. cured & $\%$ cured & No. cured & $\%$ cured \\
\hline Schistosomiasis cases $(n=27)$ & 4 & 14.8 & 1 & 3.7 \\
\hline Fascioliasis cases $(n=16)$ & 0 & 0.0 & 0 & 0.0 \\
\hline
\end{tabular}

follow-up period $(P>0.05)$ and only $0.1 \%$ reduction in the second period (Table 2).

\section{Discussion}

According to Southgate, controversy surrounds the schistosomicidal action of Mirazid [22]. In the present study, schistosomiasis cure rates evaluated 1 and 2 months after Mirazid treatment were only $14.8 \%$ and $3.7 \%$ respectively. Furthermore, a negligible reduction in GMEC was observed among uncured individuals assessed 2 months after receiving Mirazid. This denotes the very low efficacy of the drug in schistosomiasis. On the other hand, Mirazid was completely ineffective in patients infected with Fasciola spp., who showed only an initial, transient nonsignificant reduction in GMEC.

When drug efficacy is evaluated with insensitive parasitological techniques, the cure rate is likely to be overestimated and the number of eggs passed in the faeces underestimated
[23]. The quality of slide preparation, as well as technicians' expertise, influences the accuracy of the parasitology results. This is especially important in light of infections that can be easily missed even if more than one slide is examined. In the present study, we maximized the sensitivity of the Kato-Katz technique by examination of 4 slides prepared from stool samples collected on 2 consecutive days [24,25]. Technicians were of high professional calibre and quality control measures were followed in both slide preparation and examination to ensure credibility and enhance the reliability of the parasitological diagnosis.

In the present study, 4 schistosomiasis and 2 fascioliasis cases identified in the initial survey were found to be parasitologically negative when re-examined 1 day before treatment although they did not receive any antiparasitic drugs. This may be due to spontaneous cure or, in the case of fascioliasis, false infection. Absence of eggs was reported in 26\% of schistosomiasis patients re-examined within 5-6weeks [17].Inclusionofthese cases would result in over-estimation of

\begin{tabular}{|c|c|c|c|c|c|c|}
\hline \multirow{2}{*}{$\begin{array}{l}\text { Type of infection/time } \\
\text { after treatment }\end{array}$} & \multirow[t]{2}{*}{ No. of cases } & \multicolumn{2}{|c|}{ Egg count: } & \multirow[t]{2}{*}{$\%$ change } & \multirow[t]{2}{*}{$t$-value ${ }^{a}$} & \multirow[t]{2}{*}{$P$-value } \\
\hline & & Range (epg) & GMEC (SD) & & & \\
\hline \multicolumn{7}{|l|}{ Schistosomiasis cases } \\
\hline Before treatment & 27 & $6-708$ & $63.5(163.5)$ & - & - & - \\
\hline After 1 month & 23 & $6-906$ & $74.2(216.2)$ & +16.8 & 0.127 & 0.900 \\
\hline After 2 months & 26 & $6-768$ & $61.3(196.4)$ & -3.5 & 0.954 & 0.354 \\
\hline \multicolumn{7}{|l|}{ Fascioliasis cases } \\
\hline Before treatment & 16 & $12-606$ & 77.9 (171.9) & - & - & - \\
\hline After 1 month & 16 & $12-180$ & $55.0(49.4)$ & -29.4 & 1.187 & 0.254 \\
\hline After 2 months & 16 & $12-420$ & 77.8 (121.9) & -0.1 & 0.004 & 0.997 \\
\hline
\end{tabular}

aersus pre-treatment GMEC.

egp = eggs per gram; GMEC = geometric mean egg count; $S D=$ standard deviation. 
the cure rate, especially in studies involving longer follow-up periods.

It is unlikely that variation in strain susceptibility among different localities can account for the discrepancy among studies. Reports from rural areas of nearby governorates (El-Fayoum and Giza) showed discrepant results $[11,17]$.

Authors recommending the use of Mirazid have reported that its chemotherapeutic action was less evident on immature worms [14]. Therefore, in areas where individuals are simultaneously infected with adult schistosomes and the juvenile stages of the parasite, parasitological cure rates may be underestimated to some extent. New infection following drug intake may also result in apparently low response to the drug. Yet it is unlikely that these are the only explanations for the observed low cure rate, since the transmission rate is not high in the study area in view of the low prevalence and light intensity of infection [19].

On the other hand, improper administration of the drug, inadequate doses and/or poor patient compliance may result in treatment failure. The low schistosomiasis cure rates $(9.1 \%$ and $8.9 \%$ ) reported by Botros et al. were attributed to employing a suboptimal dose of Mirazid ( $300 \mathrm{mg} /$ day for 3 days) [17]. In the present study, we used the maximum recommended dose of Mirazid ( $600 \mathrm{mg} /$ day for 6 days) and proper intake of the full drug course was assured by strict supervision of capsule administration. Vomiting was not reported among the treated cases. Nevertheless, we did not detect satisfactory cure or a significant change in GMEC of uncured patients, and eggs were still viable after treatment. This observed weak anti-schistosomal activity of Mirazid was supported by Barakat et al. [18].

In conclusion, the present study did not reveal any fasciolicidal activity of myrrh and demonstrated its very week anti-schistosomal action. The use of such an ineffective drug is likely to increase patients' morbidity and might endanger the achievements of the schistosomiasis control strategy in Egypt.

\section{Acknowledgements}

This work was supported by the Medical Research Institute, Alexandria University. Egypt. The authors are grateful to Dr Omima Gaber Yassein, lecturer in medical biostatistics, Medical Research Institute, Alexandria University for statistical analysis.

\section{References}

1. Massoud AM, Galal MM, Bennett JL. Experimental studies demonstrating the anti-schistosomal activity of myrrh, cammiphora molmol. Proceedings of the 45th Annual Meeting of the American Society of Tropical Medicine and Hygiene, 1996, Baltimore, Maryland. Supplement to American Journal of Tropical Medicine and Hygiene, 55(2 suppl.):233-234.

2. Massoud AM, Salama O, Bennett JL. Efficacy, toxicity and side effects of a new antischistosomal drug derived from myrrh. Proceedings of the 46th Annual Meeting of the American Society of tropical Medicine and Hygiene.1997, Florida. Supplement to American Journal of Tropical Medicine and Hygiene, 57(3 Suppl.):244.

3. Sheir $Z$ et al. A safe, effective, herbal antischistosomal therapy derived from myrrh. American Journal of Tropical Medicine and Hygiene, 2001, 65:700-704.

4. Massoud A et al. Preliminary study of therapeutic efficacy of a new fasciolicidal drug derived from Commiphora molmol (myrrh). American Journal of Tropical Medicine and Hygiene, 2001, 65:96-99.

5. Badria F et al. Mirazid: a new schistosomicidal drug. Pharmaceutical Biology, 2001, 39:127-131.

6. Gaballah M et al. Control of schistosomiasis in a rural area using a new safe effective herbal treatment. Journal of Environmental Science, 2001, 21:63-84.

7. Motawea SM et al. Control of Fasciola in an Egyptian endemic rural area by a safe, effective fasciolicidal herbal drug. Journal of Environmental Science, 2001, 21:85-104.

8. Hamed MA, Hetta MH. Efficacy of Citrus reticulata and Mirazid in treatment of Schistosoma mansoni. Memórias do Instituto Oswaldo Cruz, 2005, 100:771-778

9. Mahmoud M S, Abou-El Dobal S, Soliman K. Immune Response in Fasciola gigantica experimentally infected rabbits treated with either carnosine or Mirazid ${ }^{\circledR}$. Research Journal of Parasitology, 2008, 3:40-49
10. El Baz MA et al. Clinical and parasitological studies on the efficacy of Mirazid in treatment of schistosomiasis haematobium in Tatoon, Etsa Center, El Fayoum Governorate. Journal of the Egyptian Society of Parasitology, 2003, 33:761-767.

11. Abo-Madyan AA, Morsy TA, Motawea SM. Efficacy of myrrh in the treatment of schistosomiasis (haematobium and mansoni) in Ezbet El-Bakly, Tamyia Center, El-Fayoum Governorate, Egypt. Journal of the Egyptian Society of Parasitology, 2004, 34:423-446.

12. Abo-Madyan AA et al. Clinical trial of Mirazid in treatment of human fascioliasis, Ezbet El-Bakly (Tamyia Center) Al-Fayoum Governorate. Journal of the Egyptian Society of Parasitology, 2004, 34:807-818.

13. Soliman OE et al. Evaluation of myrrh (Mirazid) therapy in fascioliasis and intestinal schistosomiasis in children: immunological and parasitological study. Journal of the Egyptian Society of Parasitology, 2004, 34:941-966.

14. Massoud AM et al. Evaluation of schistosomicidal activity of myrrh extract: parasitological and histological study. Journal of the Egyptian Society of Parasitology, 2004, 34(3 Suppl.):1051-1076.

15. El-Mathal EM, Fouad MA. Human fascioliasis among immigrant workers in Saudi Arabia. Journal of the Egyptian Society of Parasitology, 2005, 35(3 Suppl.):1199-1207.

16. Botros $\mathrm{S}$ et al. Lack of evidence for an antischistosomal activity of myrrh in experimental animals. American Journal of Tropical Medicine and Hygiene, 2004, 71:206-210.

17. Botros $S$ et al. Efficacy of Mirazid in comparison with praziquantel in Egyptian Schistosoma mansoni-infected school children and households. American Journal of Tropical Medicine and Hygiene, 2005, 72:119-123.

18. Barakat R, Elmorshedy H, Fenwick A. Efficacy of myrrh in the treatment of human schistosomiasis mansoni. American Journal of Tropical Medicine and Hygiene, 2005, 73:365-367. 
19. Allam AF et al. Assessing the marginal error in diagnosis and cure of Schistosoma mansoni in areas of low endemicity using Percoll and PCR techniques. Tropical Medicine and International Health, 2009, 14(3):316-321.

20. Katz N, Chaves A, Pellegrino J. A simple device for quantitative stool thick smear technique in schistosomiasis mansoni. Revista do Instituto de Medicina Tropical de São Paulo, 1972, 14:397-400.

21. Additional techniques for stool examination. In: Garcia LS, ed. Diagnostic medical parasitology, 4th ed. Washington DC, American Society for Microbiology Press, 2001:786-801.

22. Southgate VR et al. Towards control of schistosomiasis in subSaharan Africa. Journal of Helminthology, 2005, 79:181-185.
23. Utzinger J et al. Efficacy of praziquantel against Schistosoma mansoni with particular consideration for intensity of infection. Tropical Medicine and International Health, 2000, 5:771-778.

24. Utzinger J et al. Relative contribution of day-to-day and intraspecimen variation in faecal egg counts of Schistosoma mansoni before and after treatment with praziquantel. Parasitology, 2001, 122:537-544.

25. El-Morshedy $\mathrm{H}$ et al. Intra-specimen and day-to-day variations of Fasciola egg counts in human stools. Eastern Mediterranean Health Journal, 2002, 8:619-625.

\section{World Health Statistics 2010}

World Health Statistics 2010 contains WHO's annual compilation of data from its 193 Member States, and includes a summary of progress towards the health-related Millennium Development Goals and targets.

It provides a comprehensive summary of the current status of national health and health systems including; mortality and burden of disease, causes of death, reported infectious diseases, health service coverage, risk factors, health systems resources, health expenditures, inequities and demographic and socioeconomic statistics.

The publication is available in 6 languages including Arabic (http://www.who.int/whosis/whostat/AR_WHS10_Full.pdf) 